\title{
Assessment and Mapping of Potential Storm Surge Impacts on Global Population and Economy
}

\author{
Jiayi Fang $\cdot$ Shao Sun $\cdot$ Peijun Shi $\cdot$ \\ Jing'ai Wang
}

Published online: 13 December 2014

(c) The Author(s) 2014. This article is published with open access at Springerlink.com

\begin{abstract}
With global climate change, population growth, and economic development in the twenty-first century, large cyclonic storm surges may result in devastating effects in some coastal areas of the world. However, due to the deficiency of global data and large-scale modeling efforts, the assessment and mapping of potential storm surge impacts at the global level are limited. In this article, the potential inundated area of global coastal zones is projected using information diffusion theory, based on the historical hourly sea-level observation records from the University of Hawaii Sea Level Center (UHSLC), considering variations in coastal morphology and tropical cyclone tracks. Combined with global demographic and GDP data, population and GDP at risk of storm surge impacts are calculated, mapped, and validated through the comparison
\end{abstract}

J. Fang $\cdot$ S. Sun $\cdot$ P. Shi $(\bowtie)$

State Key Laboratory of Earth Surface Processes and Resource Ecology, Beijing Normal University, Beijing 100875, China

e-mail: spj@bnu.edu.cn

J. Fang $\cdot$ S. Sun $\cdot$ P. Shi

Academy of Disaster Reduction and Emergency Management, Ministry of Civil Affairs and Ministry of Education,

Beijing 100875, China

P. Shi

Key Laboratory of Environmental Change and Natural Disasters of Ministry of Education, Beijing Normal University,

Beijing 100875, China

J. Wang

School of Geography, Beijing Normal University,

Beijing 100875, China

J. Wang

Key Laboratory of Regional Geography, Beijing Normal University, Beijing 100875, China with historical losses. The resulting potential impact maps provide a preliminary outlook on risks that may help governments of countries to make storm surge disaster prevention and reduction plans.

Keywords Global coastal zone - Information diffusion · Potential impact assessment $\cdot$ Storm surge

\section{Introduction}

Storm surges are characterized by the sudden occurrence of rising water and waves and are the most serious natural disaster among marine disasters. Storm surges are primarily caused by strong winds pushing on the water surface and low atmospheric pressure associated with cyclone storms, causing the water to pile up above normal levels (Feng 1982). Severe storm surges with destructive power could occur when abnormal weather systems and astronomical high tides appear simultaneously in an area with susceptible geographic conditions such as flat coast (Le 1998). As this study uses hourly-observed sea-level data, storm surge in this article refers to the combination of mean sea level, tidal wave, and storm surge.

Scientific evidence from the Intergovernmental Panel on Climate Change (IPCC) Fifth Report (AR5) (IPCC 2013) indicates that climate change will intensify storm surges. As sea level rises due to the thermal expansion and melting of glaciers and ice sheets (Rahmstorf 2007), surges will be elevated. Secondly, as sea-surface temperature is higher (Knutson and Tuleya 2004), the intensity and frequency of storm surges is likely to increase.

The low elevation coastal zones around the world cover $2 \%$ of the world's land area but contain $10 \%$ of the world's population (McGranahan et al. 2007), as well as 
important megacities and ports (Hanson et al. 2011). These important centers of population, economy, and social development in a country's coastal areas are also places where natural disasters occur frequently. Storm surges significantly and adversely impact the natural environment and human society in the coastal zones (Von Storch and Woth 2008; Lin et al. 2012).

At the regional scale, coastal countries and regions around the world have developed a wide range of storm surge risk assessment. Many studies on storm surge mainly focus on numerical simulation. Existing storm surge assessment models-for example, SLOSH, DELFT3D, MIKE 12, ADCIRC, GCOM 2D/3D, and TAOS (Shi et al. 2013)—can accurately simulate storm surge processes in local coastal areas, but are not applicable to a wider area, or the global scale. Those complicated models not only need high-performance computation and high-resolution data, which are usually unavailable, but also are costly to use and timeconsuming. Many previous studies have surveyed severe impacts and assessed risks in regional case studies, for example, for Copenhagen (Hallegatte et al. 2011); Shanghai (Wang et al. 2012), and New York (Lin et al. 2010).

Risks of storm surge at a global scale are usually assessed with a wide range of sea-level rise, flood, and tropical cyclone projections (Nicholls et al. 1999; Hinkel et al. 2014). Dasgupta et al. (2009) explored the implications for 84 developing countries and 577 of their cyclone-vulnerable coastal cities with populations greater than 100,000. However, systematic assessment of storm surge risks should not only be concerned with the intensity and frequency of the hazard, but also with the vulnerability of elements exposed to its impact. Cutter et al. (2000) emphasized the social vulnerability of coastal communities. Nicholls et al. (2008) stressed the influence of non-climatic environmental change and socioeconomic changes.

Among all the large-scale disaster risk database and disaster risk atlases, such as the Disaster Risk Index and the Hotspots Atlas (Dilley 2005; Peduzzi et al. 2009) whose risk assessments were based on EM-DAT historical records, few have published storm surge risk maps at the global scale. The difficulties in assessing and mapping storm surge risks on a global scale have been generally ascribed to the deficiency of global data with a high resolution and the complexity of the global coastal system. Taking the complicated interactions between risk elements and availability of data into consideration, this study aimed to develop a method to assess the potential storm surge impact on populations and economies more systematically on the global scale.

Based on the theoretical framework of natural disaster system analysis (Shi 1996, 2002), this study maps potential storm surge impacts on populations and economies caused by tropical cyclones on the basis of three key factors: storm surge hazard, exposed elements, and natural environmental conditions. We use historical water-level records observed at hourly intervals from the University of Hawaii Sea Level Center (UHSLC) to analyze the intensity of storm surges by applying the information diffusion theory. Storm surge intensity is simulated by considering the different types of coastline and tracks of tropical cyclones at a global scale. For the analysis of storm surge impacts, both population density and GDP data are taken into account. The global database and methodology for storm surge impact assessment and mapping, especially the information diffusion statistical method for estimating hazard intensity, are briefly described in Sect. 2. Areas inundated by storm surges and maps of potential storm surge-affected populations and economies at the global scale are presented in Sect. 3. Section 4 presents the conclusions and further improvements that need to be made.

\section{Data and Method}

This study compiled a global database that contains a large set of observations and statistical data gathered from various sources for assessing potential storm surge impacts on populations and economies. The information diffusion method was used to calculate relative sea-level rise caused by storm surges (hazard intensity). Global expected annual maximum relative water level rise was obtained by interpolating the tidal station estimations through inverse distance weighted interpolation method. GIS tools were used to create the potential affected population and GDP maps.

\subsection{Datasets}

The datasets used are listed in Table 1. The database includes environmental, hazard, and exposure data and historical disaster records. The environmental data include global coastal typology and terrain slope. The hazard data include the global hourly research quality sea level station observations. The observed sea level can be considered as a combination of mean sea level, tidal wave, and storm surge. Menéndez and Woodworth (2010) have used the same dataset to investigate the worldwide patterns of historical extreme sea level changes by means of an extreme value analysis. They examined two variables - total water level elevation for each station and the surge componentto investigate the relationship between water levels and climate indices. As the focus of this study is on the effect caused by extreme high water levels, total water level elevation is used in our analysis.

The environmental data include global coastal typology and terrain slope. The coastal typology consists of a ribbon of grid cells at $0.5^{\circ}$ resolution, located along the entire 
Table 1 Sources and descriptions of the datasets used for assessing and mapping potential storm surge impacts at a global scale

\begin{tabular}{llll}
\hline Dataset & Data source & Resolution & Time \\
\hline Terrain slope & IIASA and FAO & $1 \mathrm{~km} \times 1 \mathrm{~km}$ & 2002 \\
Global coastal typology & Utrecht University & $0.5^{\circ}$ & Hourly \\
Hourly research quality sea & University of Hawaii Sea & $1 \mathrm{~km} \times 1 \mathrm{~km}$ & Varied \\
level station data & Level Center (UHSLC) & $1 \mathrm{~km} \times 1 \mathrm{~km}$ & 2010 \\
Global population density data & Oak Ridge National Laboratory (ORNL) & 2006 \\
Global GDP distribution data & NOAA & Vector \\
Historic tropical cyclone tracks & NASA & Global Risk Data Platform (GRDP) & $1856-2006$ \\
Tropical cyclone surge events & &
\end{tabular}

global coastline (Dürr et al. 2011). The exposure data include global demographic and economic datasets from Oak Ridge National Laboratory (ORNL) (Bright et al. 2011) and the National Oceanic and Atmospheric Administration (NOAA) (Ghosh et al. 2010) of the United States respectively, both with $1 \mathrm{~km} \times 1 \mathrm{~km}$ spatial resolution. The historical disaster record data include historic tropical cyclone tracks from the National Hurricane Center and the Joint Typhoon Warning Center and tropical storm surge events that include a compilation of estimated storm surges triggered by tropical cyclones from 1975 to 2007.

\subsection{Method}

Potential storm surge impact is defined as the possible losses caused by a storm surge. Figure 1 shows the flowchart for mapping the potential storm surge-affected population and GDP globally.

\subsubsection{Fuzzy Information Processing}

The hazard dataset covers 596 tide gauges along the global coastline, but the length of hourly sea-level records of each tide gauge ranges from 1 to 100 years. Only 315 tide gauges have records of more than 5 years (Fig. 2). Ideally, 19 years' records are needed if using the traditional general extreme value theory to calculate hazard intensity, that is, water level rise. However, if we remove the data of stations with less than 19 years' records, nearly 200 stations will be excluded from the calculation. In order to make full use of the available global dataset for better global coverage of potential storm surge impact assessment, information diffusion theory was introduced to estimate the maximum relative sea level. Information diffusion theory is a fuzzy mathematic method that makes the dataset elements setvalued by taking advantage of the fuzzy information optimally (Huang 2012). This method has been applied in the risk assessment of storm surges in the coastal areas of the Bohai Sea and the Yellow Sea in China. The application in these examples shows that the calculated results obtained by information diffusion are reliable by comparing and verifying with the results from the Gumbel distribution (Qi et al. 2010).

The study assumes that storm surge is a stochastic Markov chain process and its state changes according to a transition rule that only depends on the known past $n$ years' state. The diffusion function of the normal information diffusion model is:

$f_{i}\left(u_{j}\right)=\frac{1}{h \sqrt{2 \pi}} \exp \left[-\frac{\left(x_{i}-x_{j}\right)^{2}}{2 h^{2}}\right]$

where $h$ is the diffusion coefficient, which is determined by the maximum $x_{\max }$, minimum $x_{\min }$ and sample size $n$ of $X$ as follows:
Fig. 1 Flowchart for assessing potential global population and GDP affected by storm surges

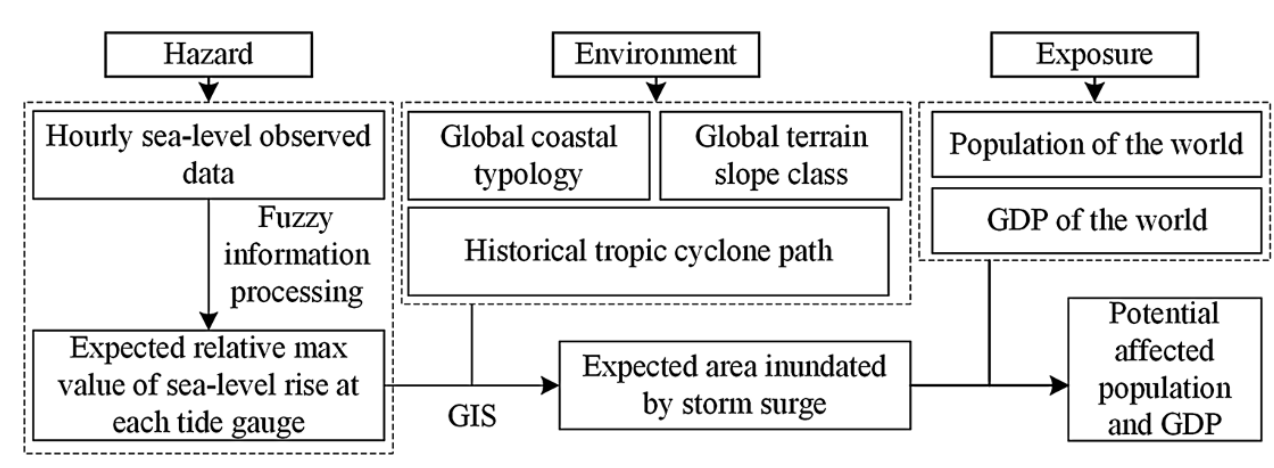


Fig. 2 Length of tide gauge records ( $Y$ year)

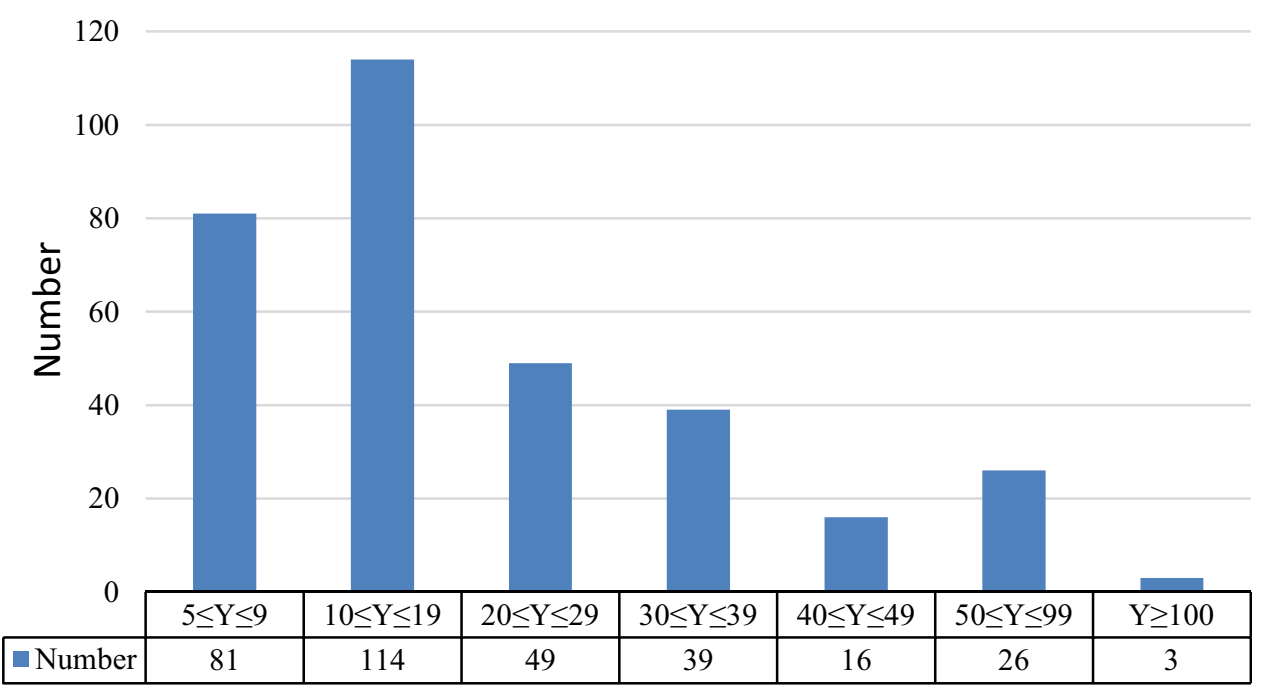

$h= \begin{cases}0.8146\left(x_{\max }-x_{\min }\right), & n=5 \\ 0.5690\left(x_{\max }-x_{\min }\right), & n=6 \\ 0.4560\left(x_{\max }-x_{\min }\right), & n=7 \\ 0.3860\left(x_{\max }-x_{\min }\right), & n=8 \\ 0.3362\left(x_{\max }-x_{\min }\right), & n=9 \\ 0.2986\left(x_{\max }-x_{\min }\right), & n=10 \\ 2.6851\left(x_{\max }-x_{\min }\right) /(n-1), \quad n \geq 11\end{cases}$

Based on the diffusion function, we can diffuse the information of each individual in the sample $X$ to all of the elements in the monitoring space $U$. Define the membership function of the corresponding fuzzy subset of the individual $x_{i}$ as follows:

$\mu_{x_{i}}\left(u_{j}\right)=f_{i}\left(u_{j}\right) / \sum_{j=1}^{m} f_{i}\left(u_{j}\right)$

$\mu_{x_{i}}\left(u_{j}\right)$ is called a normal information distribution of $x_{i}$. Let

$t\left(u_{j}\right)=\sum_{i=1}^{n} \mu_{x_{i}}\left(u_{j}\right)$

$T=\sum_{j=1}^{n} t\left(u_{j}\right)$

where $t\left(u_{j}\right)$ in Eq. (4) is called the primary information structure of the record. $T$ in Eq. (5) is the sum of the individual numbers of $u_{j}$. So

$P\left(u_{j}\right)=\frac{t\left(u_{j}\right)}{T}$

where $P\left(u_{j}\right)$ is the frequency value that corresponds to $u_{j}$, which approximately equals the estimated value of the probability. Therefore, the probability that $x \geq u_{j}$ is:

$P\left(x \geq u_{j}\right)=\sum_{j=1}^{m} \frac{t\left(u_{j}\right)}{T}$

$p\left(x \geq u_{j}\right)$ is the exceedance probability that the storm surge occurrence exceeds the intensity $u_{j}$.
We used the yearly maximum water level as the indicator of hazard intensity:

(1) Calculate the mean of water level at each tidal station $\left(H_{\text {mean }}\right)$ by using the hourly dataset of water levels during $n$ years;

(2) Construct the annual maximum water levels datasets $H_{\max }=\left\{h_{\max 1}, h_{\max 2}, \ldots, h_{\operatorname{maxn}}\right\}$; then minus the mean sea level $H_{\text {mean }}$, to obtain the annual maximum relative water level rise dataset $H_{\text {relative }}=\left\{h_{1}, h_{2}, \ldots, h_{\mathrm{n}}\right\}$;

$H_{\text {relative }}=H_{\text {max }}-H_{\text {mean }}$

(3) Obtain the probability distribution curve of $H_{\text {relative }}=$ $\left\{h_{1}, h_{2}, \ldots, h_{\mathrm{n}}\right\}$ which refer to $x$ by using the information diffusion method, $U=$ $\left\{u_{j} \mid j=1, \ldots, 501\right\}=\{0,1,2, \ldots, 499,500\} \quad$ which means sample's domain, here we assume the maximum relative water level is $5 \mathrm{~m}$ (Qi et al. 2010). And calculate the expected value $H$ of the maximum relative water level.

\subsubsection{GIS Analysis}

The natural environment has a significant influence on the damages caused by various magnitudes of storm surges. Considering the complexity of the coastal environment and the uneven distribution of tidal stations, ordinary interpolation methods that extend hazard intensity to each shoreline along the coast could not well reflect the regional differences in hazard intensity. Thus, this study uses the inverse distance weighted interpolation method to extrapolate the expected annual maximum of relative water level rise (storm surge intensity). Area-altitude analysis is used to calculate the potential maximum inundated area in ArcGIS.

The interpolation is done as follows: First, based on the coastal geological environment, the primary partitions is to 
classify coastal zones into bedrock coasts and plain coasts (Dürr et al. 2011). Storm surges reach bedrock coasts through a shorter distance than plain coasts. However, the topography of loose sedimentary plain coasts is usually flat, especially silty mud coasts, which are open and flat with a slope of less than $0.5 \%$. Taking into account the historical track records of tropical cyclones, we excluded the coastlines north of the Arctic Circle, south of $60^{\circ} \mathrm{S}$ and within $5^{\circ}$ latitude of the equator where no tropical cyclones form. On the basis of the primary partitions, we divided global coastlines into plainstorm, plain-nostorm, bedrock-storm, bedrock-nostorm coastal areas. As the next step, considering the origin area of the cyclones and their paths, as well as land barriers, we divided storm coast into 10 zones: northeast Pacific coast, northwest Pacific coast, southwest Pacific coast, northeast Atlantic coast, northwest Atlantic coast, Arabian Sea coast, bay of Bengal coast, eastern coast of Southern Indian Ocean, western coast of Southern Indian Ocean, and coast of islands. Finally, the expected annual maximum of relative water level rise, $H$, values in all coastal areas of the world were obtained by interpolating the $H$ values at each tidal station in each zone through the inverse distance weighted interpolation method (Watson and Philip 1985) in ArcGIS.

After interpolating the expected $H$ values at the global scale, we calculated the potential maximum inundated area. Slope is regarded as the most important preparatory factor for inundated area mapping and it is calculated as a ratio of rise to run in which run is the horizontal distance and rise is the vertical distance. Terrain slope is divided into 8 classes: $0-0.5 ; 0.5-2 ; 2-5 ; 5-8 ; 8-16 ; 16-30 ; 30-45$; and $>45 \%$. The potential maximum inundated distance, $D_{\text {inundated }}$, is calculated from the slope dataset with Eq. (8):

$$
\begin{aligned}
& D_{\text {inundated }} \\
& = \begin{cases}H \times 2000, & \text { slope: } 0-0.5 \% \\
\frac{H}{\min \{\text { slope }\}}, & \text { slope: } 0.5-2,2-5, \ldots, 30-45, \text { and }>45 \%\end{cases}
\end{aligned}
$$

Generally, we assume the maximum inundated distance is $10 \mathrm{~km}$ away from coastline (Fang et al. 2011). The potential maximum inundated area at the global scale is delineated by using the area-altitude analysis (Strahler 1952) in ArcGIS.

By superimposing the global population density and GDP distribution data on the inundated area map, the global population and GDP that can be potentially affected by storm surges are calculated.

\section{Results}

The results of the storm surge analysis are presented in a series of maps including storm surge intensity, coastal inundated area, and potential affected population and GDP. This section presents these maps and discusses the spatial distribution of the estimations. The spatial resolution of these maps is $1 \mathrm{~km} \times 1 \mathrm{~km}$.

\subsection{Storm Surge Intensity}

Magnitude of maximum relative water level rise is depicted in Fig. 3. Due to the high intensity of tropical cyclones, storm surges can generally bring about dramatic changes in sea level. Maximum relative water level rise of $300 \mathrm{~cm}$ or more are found along the western European coast, northern Australia, the Gulf of Alaska, and East China Sea. This pattern found from this research is similar with Menéndez and Woodworth (2010). Figure 4 shows that maximum relative water level rise is mainly in the $60-160 \mathrm{~cm}$ range, with the total number of stations of $224,71 \%$ of all stations. Maximum relative water level rise of $300 \mathrm{~cm}$ or higher is estimated for 17 stations, about $5.4 \%$ of all stations.

\subsection{Inundated Area}

The topography of coastal areas plays an important role when we calculate potential inundated areas. The potential inundated areas are concentrated on coastal plains that are frequently hit by strong cyclones. These areas are mainly located along the coasts of East Asia, western Europe, northern Australia, and eastern and western North America (Fig. 5). Although on bedrock coasts inundated areas may not be wide, such areas could also experience severe damage due to an extreme rise of water level. The west coast of Canada is an example of this.

\subsection{Affected Population}

A large variability of the potential affected population exists due to the huge differences of population density at the grid level $(1 \mathrm{~km} \times 1 \mathrm{~km})$ and potential inundated area. High risk areas for population exposure to storm surges are located in the Caribbean region, the Bay of Bengal, and East Asia (Fig. 6). Although some regions have a high value of inundated area, the risk of population exposure is low due to sparse population along the coastline-as for example, in Australia.

\subsection{Affected GDP}

A large variability of the potential affected GDP also exists due to the huge differences of GDP at the grid level. Higher economic losses will be encountered following rapid economic development of a country. Regions with potential 


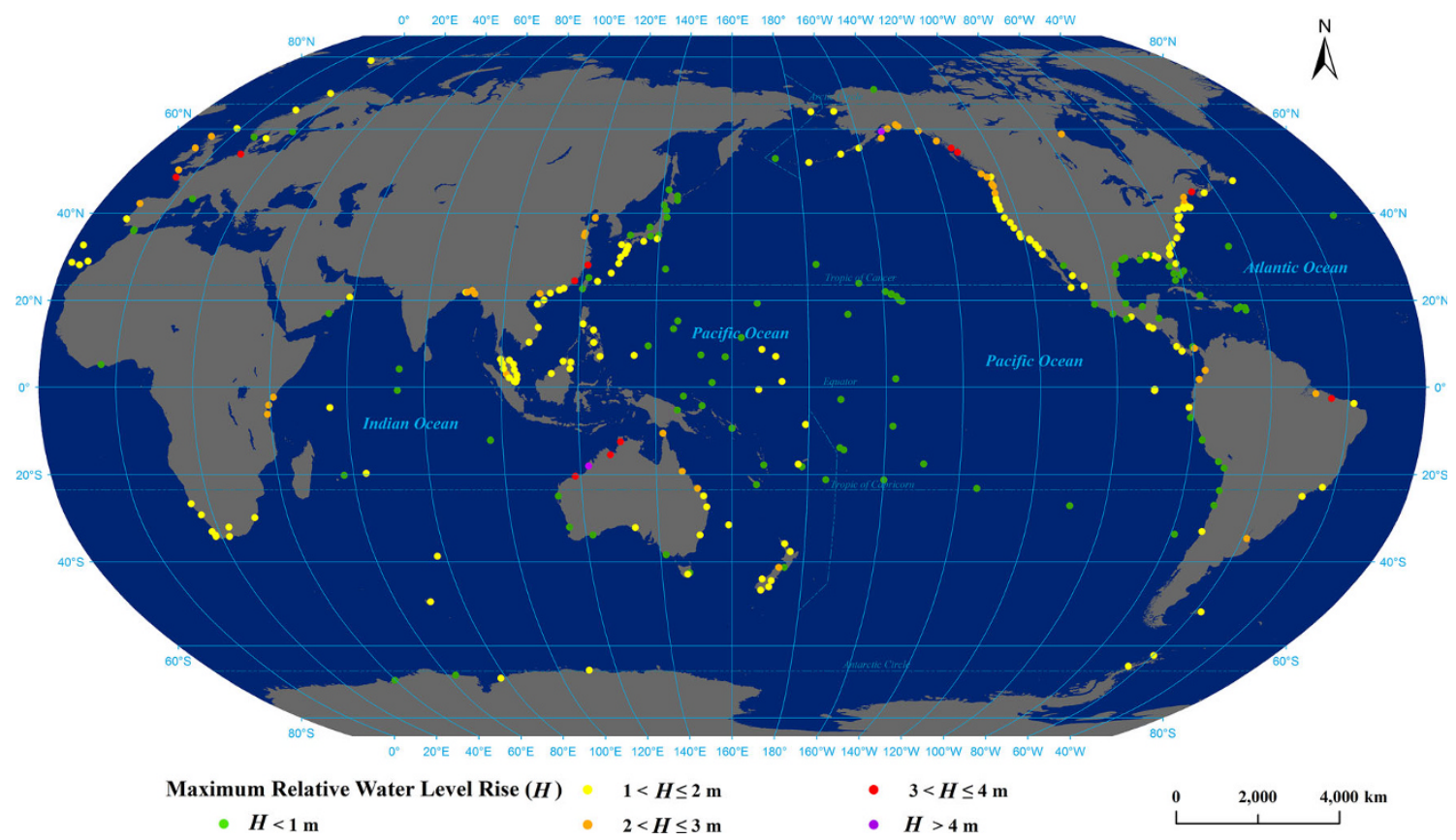

Fig. 3 Maximum relative water level rise in global coastal zones

Fig. 4 Number of stations with different maximum relative water level rise

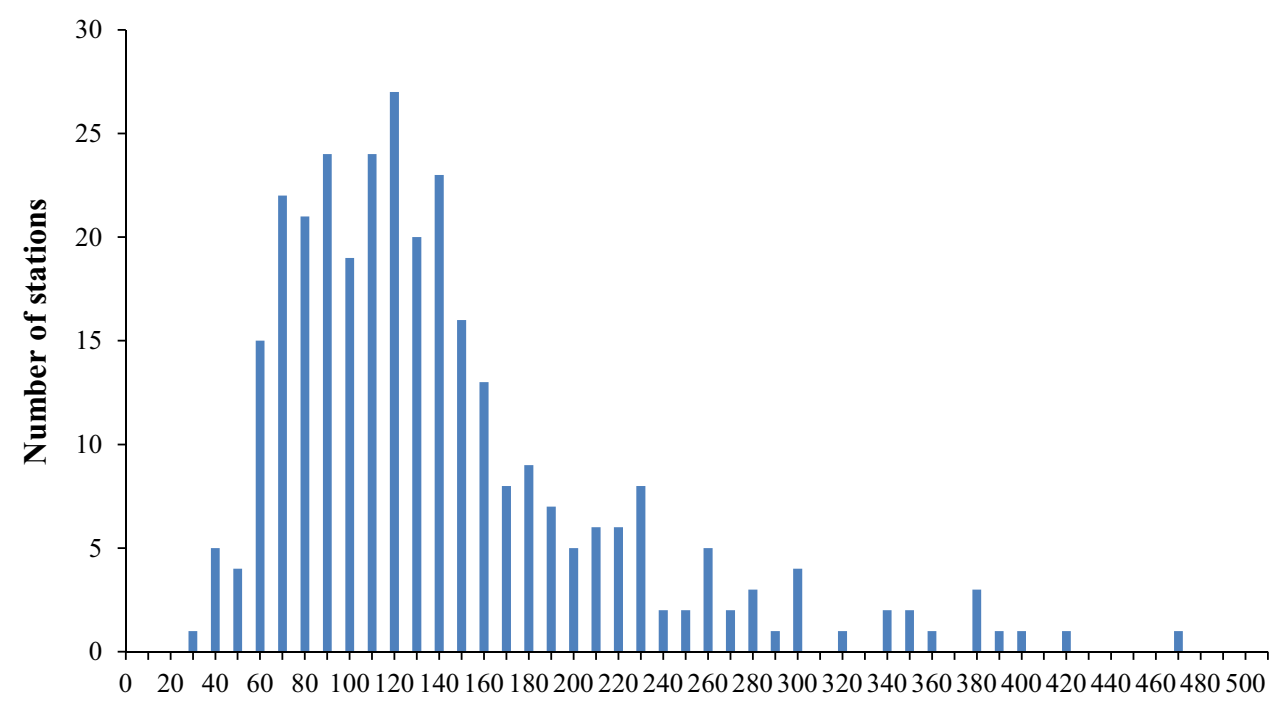
Maximum Relative Water Level Rise (cm)

high economic losses are mainly distributed in some coastal areas of England, other developed countries in Europe, the Yangtze River Delta in China, the eastern coast of the United States, and the Gulf of Mexico (Fig. 7). For the Bay of Bengal, even though it is characterized by a high risk of population exposure, the economic risk is not as remarkable because of the area's underdeveloped economies.

\subsection{Validation}

Historical loss data can to some degree reflect the spatial distribution of risks. The Global Risk Data Platform (GRDP) contains 2,033 historical storm surge disaster records, which include a compilation of storm surges triggered by tropical cyclones from 1975 to 2007, with information on the place, time, affected population, affected GDP, among others. We produced a country ranking of risk of 57 countries according to the sum of inundated areas, affected population, and GDP loss by using the historical storm surge disaster records from GRDP. Country level statistics of potential inundated area, potential affected population, and potential affected GDP are generated for this purpose. We compared the country rankings according to the statistics derived from the GRDP data with country rankings from this study to test the reliability of our results in the estimated inundated area and 


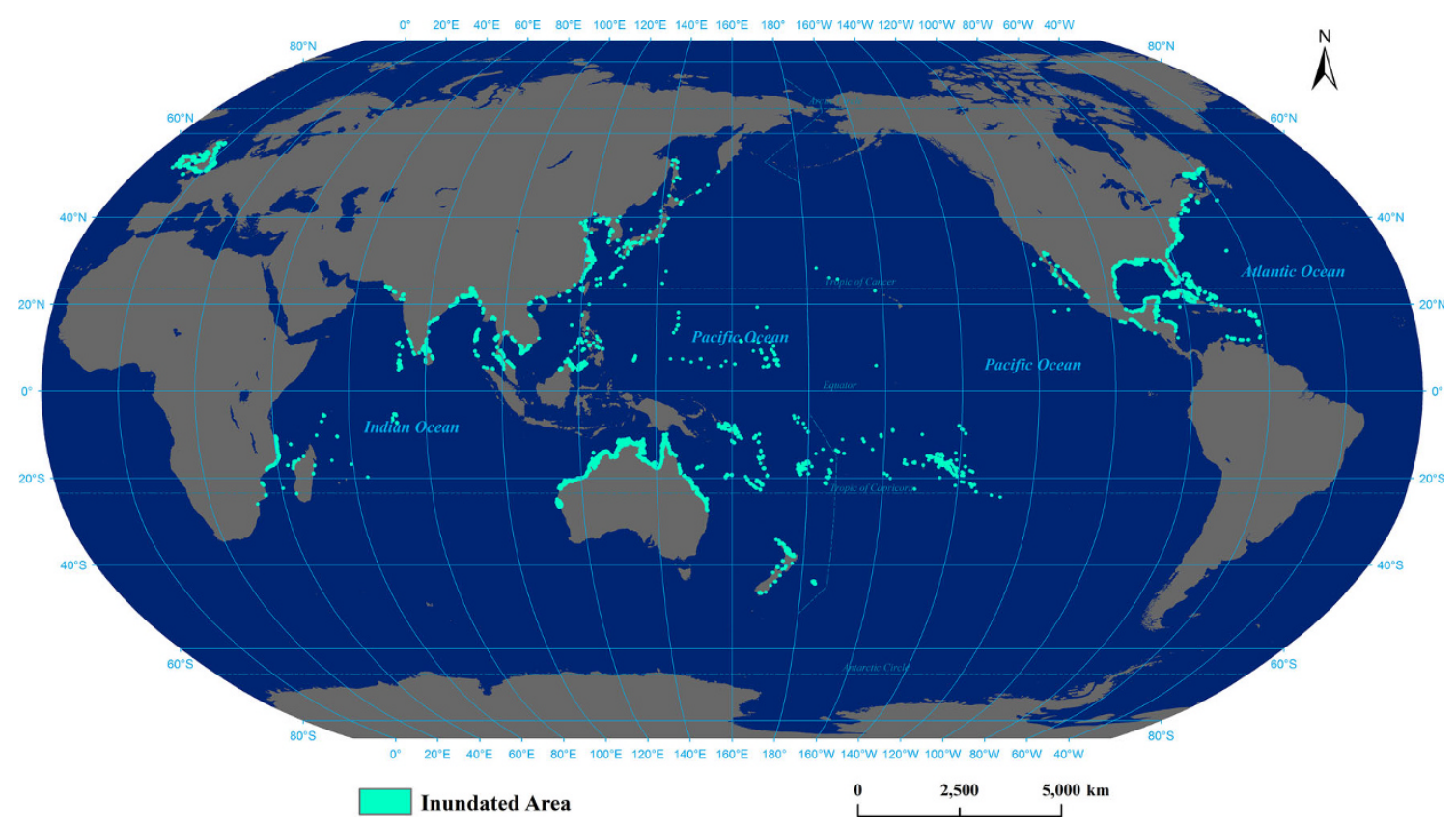

Fig. 5 Expected inundation areas of global coastal zones by storm surges

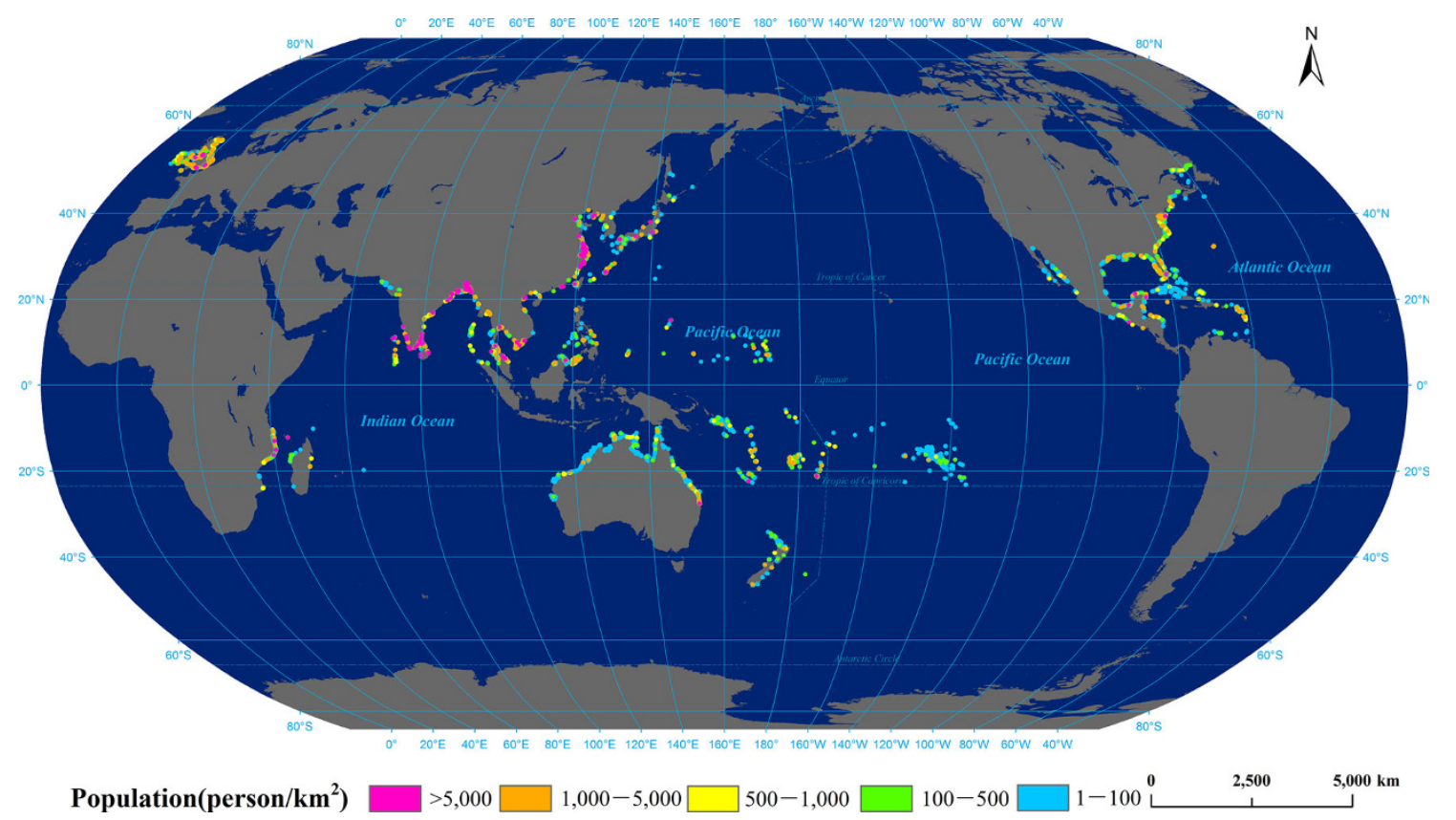

Fig. 6 Expected demographic risk of storm surge impact of the world

potential population and GDP impacts. The sample size is 57 and the top $10 \%$ countries is listed in Table 2.

For the results on inundated area, significant correlation is found at the 0.01 confidence level (bilateral), with correlation coefficient of 0.72 . The country rankings of population and GDP impacts are moderately correlated at the 0.01 confidence level (bilateral), with the correlation coefficients of 0.47 and 0.57 .

\section{Conclusion}

Using a series of available and recent global datasets from various sources, this study examined the potential global impact of storm surges on populations and economies. Storm surge disasters are usually associated with extreme precipitation and strong winds. As there is no model that is capable of performing global storm surge simulation and 


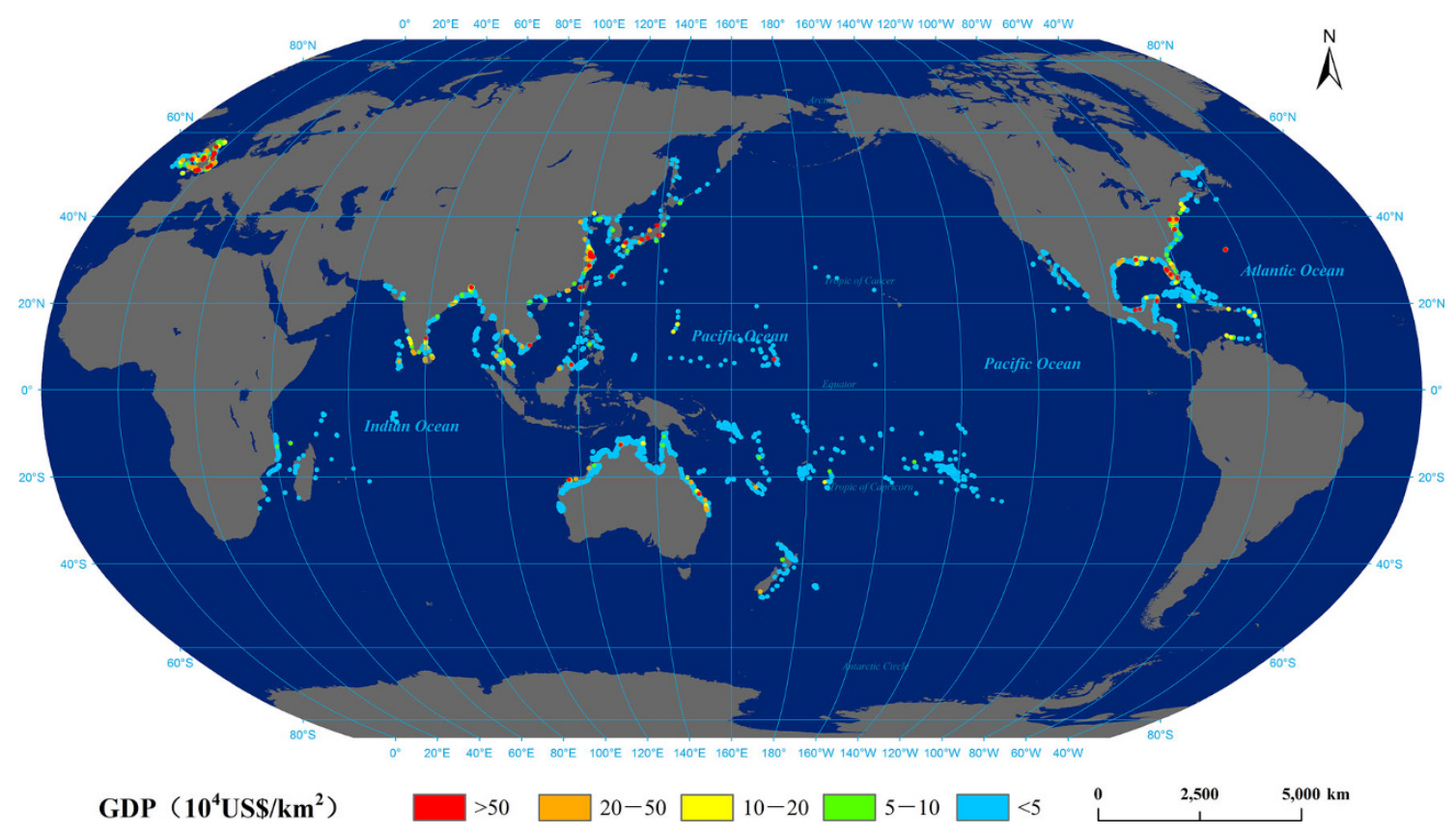

Fig. 7 Expected economic risk of storm surge impact of the world

Table 2 The top $10 \%$ countries of potential inundated area, potential affected population, and potential affected GDP by storm surges

\begin{tabular}{|c|c|c|c|c|c|c|}
\hline \multirow[t]{2}{*}{ Country Ranking } & \multicolumn{3}{|c|}{ Results from This Study } & \multicolumn{3}{|c|}{ Records from GRDP } \\
\hline & Inundated area & Affected population & Affected GDP & Inundated area & Affected population & Affected GDP \\
\hline 1 & Australia & Bangladesh & United States & United States & China & United States \\
\hline 2 & United States & India & China & Mexico & Bangladesh & China \\
\hline 3 & Mexico & China & Japan & China & India & Mexico \\
\hline 4 & Bangladesh & Vietnam & Australia & Australia & Burma & Puerto Rico \\
\hline 5 & Cuba & United States & Ireland & India & United States & India \\
\hline 6 & India & Sri Lanka & Bangladesh & Burma & Vietnam & Bangladesh \\
\hline
\end{tabular}

the datum of each tidal station is different, we adopted the fuzzy information processing method to calculate the yearly expected value of maximum relative water level rise at each tide gauge as the intensity of storm surges. Using the yearly expected value of maximum relative water level rise, we simulated the potential annual maximum inundated area, then calculated the population and GDP potentially affected annually by storm surges without taking protective measures. The comparison with historical storm surge losses indicates that the results in this study are reliable.

The two important elements of storm surge disaster risk assessment are storm surge hazard assessment and vulnerability assessment of the exposed elements. Few studies exist on storm surge disaster vulnerability and response ability. Such assessment involves many factors, including socioeconomic factors, disaster prevention engineering facilities, and non-engineering measures.
Thus, gaps in data have limited our ability to conduct a comprehensive analysis of global storm surge risks. Due to the complicated processes of storm surges, coupled with the lack of data at the global scale, it is difficult to explore detailed storm surge impacts. Losses resulting from storm surges are closely related to storm surge intensity and affected areas, terrain and landforms in disaster areas, and other natural factors. Conditions of disaster prevention facilities as well as implementation of disaster prevention and reduction measures also play major roles in reducing losses. First and foremost, the absence of a global database on shoreline protection has prevented us from incorporating the effect of existing manmade protection measures (for example, sea dikes) and natural coastal protective features (for example, mangroves) on the exposed elements. Future work should take these issues into consideration. The identification and assessment of global potential impact by storm surges promote the understanding of the spatial pattern of 
the impacts and can inform a range of disaster prevention and preparedness measures.

Acknowledgments This work was funded by the Chinese National Basic Research Program (973 Program): "Global Change and Environmental Risk Relationships and Adaptability Paradigm" (2012CB955404); the Innovative Research Group Project of National Natural Science Foundation of China (41321001); and the 111 project "Hazard and Risk Science Base at Beijing Normal University" under Grant B08008, Ministry of Education and State Administration of Foreign Experts Affairs, China. We are very thankful for the comments and suggestions by the reviewers.

Open Access This article is distributed under the terms of the Creative Commons Attribution License which permits any use, distribution, and reproduction in any medium, provided the original author(s) and the source are credited.

\section{References}

Bright, E.A., P.R. Coleman, A.N. Rose, and M.L. Urban. 2011. LandScan 2010. Oak Ridge, TN: Oak Ridge National Laboratory.

Cutter, S.L., J.T. Mitchell, and M.S. Scott. 2000. Revealing the vulnerability of people and places: A case study of Georgetown County, South Carolina. Annals of the Association of American Geographers 90(4): 713-737.

Dasgupta, S., B. Laplante, S. Murray, and D. Wheeler. 2009. Climate change and the future impacts of storm-surge disasters in developing countries. Center for Global Development Working Paper 182.

Dilley, M. 2005. Natural disaster hotspots: A global risk analysis. Washington DC: World Bank Publications.

Dürr, H.H., G.G. Laruelle, C.M. van Kempen, C.P. Slomp, M. Meybeck, and H. Middelkoop. 2011. Worldwide typology of near shore coastal systems: Defining the estuarine filter of river inputs to the oceans. Estuaries and Coasts 34(3): 441-458.

Fang, W.H., J.A. Wang, and P.J. Shi. 2011. Integrated risk governance-Database, risk map and web platform. Beijing: Science Press (in Chinese).

Feng, S.Z. 1982. Introduction to storm surge. Beijing: Science Press (in Chinese).

Ghosh, T., R. Powell, C.D. Elvidge, K.E. Baugh, P.C. Sutton, and S. Anderson. 2010. Shedding light on the global distribution of economic activity. The Open Geography Journal 3(1): 147-160.

Hallegatte, S., N. Ranger, O. Mestre, P. Dumas, J. Corfee-Morlot, C. Herweijer, and R.M. Wood. 2011. Assessing climate change impacts, sea level rise and storm surge risk in port cities: A case study on Copenhagen. Climatic Change 104(1): 113-137.

Hanson, S., R. Nicholls, N. Ranger, S. Hallegatte, J. Corfee-Morlot, C. Herweijer, and J. Chateau. 2011. A global ranking of port cities with high exposure to climate extremes. Climatic Change 104(1): 89-111.

Hinkel, J., D. Lincke, A.T. Vafeidis, M. Perrette, R.J. Nicholls, R.S.J. Tol, B. Marzeion, X. Fettweis, C. Ionescu, and A. Levermann. 2014. Coastal flood damage and adaptation costs under 21st century sea-level rise. Proceedings of the National Academy of Sciences 111(9): 3292-3297.

Huang, C.F. 2012. Risk analysis and management of natural disasters. Beijing: Science Press (in Chinese).
IPCC (Intergovernmental Panel on Climate Change). 2013. Intergovernmental panel on climate change fifth assessment report (AR5). Cambridge: Cambridge University Press.

Knutson, T.R., and R.E. Tuleya. 2004. Impact of $\mathrm{CO}_{2}$-induced warming on simulated hurricane intensity and precipitation: Sensitivity to the choice of climate model and convective parameterization. Journal of Climate 17(18): 3477-3495.

Le, K.T. 1998. The basic problem of the storm surge disaster risk assessment method in China. Marine Forecasts 15(3): 38-44 (in Chinese).

Lin, N., K.A. Emanuel, J.A. Smith, and E. Vanmarcke. 2010. Risk assessment of hurricane storm surge for New York City. Journal of Geophysical Research: Atmospheres 115(D18). doi:10.1029/ 2009JD013630.

Lin, N., K.A. Emanuel, M. Oppenheimer, and E. Vanmarcke. 2012. Physically based assessment of hurricane surge threat under climate change. Nature Climate Change 2(6): 462-467.

McGranahan, G., D. Balk, and B. Anderson. 2007. The rising tide: Assessing the risks of climate change and human settlements in low elevation coastal zones. Environment and Urbanization 19(1): 17-37.

Menéndez, M., and P.L. Woodworth. 2010. Changes in extreme high water levels based on a quasi-global tide-gauge data set. Journal of Geophysical Research: Oceans 115(C10). doi:10.1029/ 2009JC005997.

Nicholls, R.J., F.M.J. Hoozemans, and M. Marchand. 1999. Increasing flood risk and wetland losses due to global sea-level rise: Regional and global analyses. Global Environmental Change 9(S1): S69-S87.

Nicholls, R.J., P.P. Wong, V. Burkett, C.D. Woodroffe, and J. Hay. 2008. Climate change and coastal vulnerability assessment: Scenarios for integrated assessment. Sustainability Science 3(1): 89-102.

Peduzzi, P., H. Dao, C. Herold, and F. Mouton. 2009. Assessing global exposure and vulnerability towards natural hazards: The Disaster Risk Index. Natural Hazards and Earth System Sciences 9(4): 1149-1159.

Qi, P., M.J. Li, and Y.J. Hou. 2010. Risk assessment of storm surge disaster in the coastal areas of Bohai Sea and Yellow Sea based on information diffusion principle. Oceanologia Et Limnologia Sinica 41(4): 628-632 (in Chinese).

Rahmstorf, S. 2007. A semi-empirical approach to projecting future sea-level rise. Science 315(5810): 368-370.

Shi, P.J. 1996. Theory and practice of disaster study. Journal of Natural Disasters 5(4): 6-17 (in Chinese).

Shi, P.J. 2002. Theory on disaster science and disaster dynamics. Journal of Natural Disasters 11(3): 1-9 (in Chinese).

Shi, X.W., J. Tan, Z.X. Guo, and Q.Z. Liu. 2013. A review of risk assessment of storm surge disaster. Advances in Earth Science 28(8): 866-874 (in Chinese).

Strahler, A.N. 1952. Hypsometric (area-altitude) analysis of erosional topography. Geological Society of America Bulletin 63(11): 1117-1142.

Von Storch, H., and K. Woth. 2008. Storm surges: Perspectives and options. Sustainability Science 3(1): 33-43.

Wang, J., W. Gao, S. Xu, and L. Yu. 2012. Evaluation of the combined risk of sea level rise, land subsidence, and storm surges on the coastal areas of Shanghai, China. Climatic Change 115(3-4): 537-558.

Watson, D.F., and G.M. Philip. 1985. A refinement of inverse distance weighted interpolation. Geo-processing 2(4): 315-327. 